\title{
ĐÁNH GIÁ MộT Số CHỈ Số SỬ DỤNG THUỐC TẠI TRUNG TÂM Y TẾ HUYÊ̂N PHONG ĐIỀN GIAI ĐOẠN 2019-2020
}

\begin{abstract}
Nguyễn Phục Hưng
TÓM TẮT

Mục đích: Khảo sát tình hình sử dụng thuốc trong điều trị ngoại trú thông qua một số chỉ số sử dụng thuốc. Đối tượng và phương pháp: Nghiên cứu được thực hiện theo phương pháp mô tả cắt ngang với 385 đơn thuốc ngoai trú có bảo hiểm y tế. Kết quả: Số thuốc trung bình trong một đơn là 5,18. Tỷ lệ đơn thuốc có kháng sinh chiếm 35,32\%, thuốc tiêm $0,52 \%$, vitamin và corticoid chiếm tỷ lệ lần lượt là $22,60 \%, 26,20 \%$. Tỷ lệ thuốc được kể nằm trong danh mục thuốc thiết yếu là $45,64 \%$. Chi phí trung bình cho mỗi đơn thuốc là 74.590 VNĐ. Tỷ lệ chi phí cho kháng sinh chiếm $38,28 \%$, thuốc tiêm chiếm $72,77 \%$; vitamin là 11,14\%; corticoid chiếm 7,98\%. Kết luân: nqhiên cứu là tài liêu tham khảo cho các cán bô y tếvà lãnh đao về tình hình kê đơn thuốc trong điều trị ngoại trú tại 1 cơ sở y tế hạng III.
\end{abstract}

Tư khóa: Chỉ số sử dụng thuốc,kê đơn, bệnh nhân ngoại trú.

\section{SUMMARY}

ACCESSMENT OF SOME DRUG USE INDICATORS AT PHONG DIEN MEDICAL

\section{CENTER IN THE PERIOD OF 2019-2020}

Purpose:To survey the drug use among outpatient treatment by means of drug use indicators. Subjects and methods: A cross-sectional descriptive study was conducted on 385 outpatient prescriptions with health insurance. Results:The results showed that the average number of drugs in each prescription was $5.18,35.32 \%$ antibiotics, $0.52 \%$ injections, $22.6 \%$ vitamin, $26.2 \%$ corticosteroids and $45.64 \%$ essential drugs. The average prescription cost was 3.22 USD. The proportion of antibiotics, injections, vitamins and corticoids cost was $38.28 \%, 72.77 \%$, $11.14 \%$ and $7.98 \%$ respectively. Conclusion: The results of the study provide useful information for health workers and leaders on the current situation of outpatient prescription at a district (level III) healthcare facility.

Keywords: Drug use indicators, prescription, outpatient.

\section{I. ĐẶT VẤN ĐỀ}

Tình trạng lạm dụng kháng sinh, thuốc tiêm, vitamin, corticoid, kể quá nhiều thuốc cho một đơn thuốc, vẫn còn tình trạng kê đớn theo tên thương mại đối với trường hợp thuốc không có

*Trường Đại học Y Dược Cần Thơ Chịu trách nhiệm chính: Nguyễn Phục Hưng Email: phuchung275@gmail.com Ngày nhận bài: 9/1/2021

Ngày phản biện khoa học: 5/2/2021 Ngày duyệt bài: 2/3/2021 nhiều hoạt chất làm phát sinh thêm chi phí điều trị không đáng có của người bệnh. Những bất cập này đã và đang tồn tại và cần có các biện pháp khắc phục cụ thể, kịp thời nhằm hướng tới sử dụng thuốc an toàn, hợp lý và kinh tế.

II. ĐỐI TƯợNG VÀ PHƯƠNG PHÁP NGHIÊN CỨU

2.1. Đối tượng nghiên cứu. Đơn thuốc ngoại trú bảo hiểm y tế tại khoa khám của Trung tâm Y tế huyện Phong Điền từ tháng 12/2019 đến tháng 06/2020.

\subsection{Phương pháp nghiên cứu}

2.2.1. Thiết kế nghiên cứu. Nghiên cứu được thực hiện theo phương pháp mô tả cắt ngang.

2.2.2. Cõ̃ mẫu chon

- Cỡ mẫu: Số đơn thuốc cần thu thập:

$$
\mathrm{n}=\frac{Z_{(1-\alpha / 2) \cdot p \cdot(1-p)}^{2}}{d^{2}}
$$

Chọn $a=0,05$; tra bảng với $(1-a)=0,95$ thì $Z_{(1-\alpha)}=1,96$. Chọn $d=0,05$.

Thay vào công thức trên, ta có $\mathrm{n}=385$.

- Cách chọn mẫu: mỗi ngày chọn 10-15 đơn thuốc của người bệnh đến đăng kí khám bệnh ngoại trú có BHYT.

\section{KẾT QUẢ NGHIÊN CỨU}

\subsection{Số thuốc kê trung bình trong một} đơn

Bảng 3.1. Số thuốc kê trung bình trong môt đơn

\begin{tabular}{|c|c|c|c|}
\hline $\begin{array}{l}\text { Trung bình } \\
\text { chung }\end{array}$ & $\begin{array}{c}\text { Đơn } \\
\text { thuốc }\end{array}$ & $\begin{array}{c}\text { Số } \\
\text { lượng }\end{array}$ & $\begin{array}{l}\text { Tỷ lê } \\
(\%)\end{array}$ \\
\hline \multirow{2}{*}{5,18} & $\leq 3$ thuốc & 59 & 15,32 \\
\hline & $>3$ thuốc & 326 & 84,68 \\
\hline \multicolumn{2}{|c|}{ Tống } & 385 & 100 \\
\hline
\end{tabular}

Số thuốc kê trung bình trong một đơn là 5,18 ; số đơn thuốc có nhiều từ 4 thuốc trở lên (326 đơn) chiếm tỷ lệ cao hơn hẳn $(84,68 \%)$ so với các đơn có ít hơn hoặc bằng 3 thuốc (với 59 đơn thuốc chiếm tỷ lệ 15,32\%).

\subsection{Tỷ lệ đơn kể có kháng sinh}

Bảng 3.2. Tỷ lê đơn thuốc có kháng sinh

\begin{tabular}{|c|c|c|}
\hline Đơn thuốc & Số lượng & Tỷ lệ (\%) \\
\hline Không có kháng sinh & 249 & 64,68 \\
\hline Có kháng sinh & 136 & 35,32 \\
\hline Tống & $\mathbf{3 8 5}$ & $\mathbf{1 0 0}$ \\
\hline
\end{tabular}

Kết quả cho thấy số đơn có sử dụng kháng sinh chiếm tỉ lê $35,32 \%$ và số đơn không sử dụng kháng sinh chiếm số lượng lớn hơn với tỷ 
lệ 64,68\%.

Bảng 3.3. Tỷ lệ đơn thuốc phối hợp kháng sinh

\begin{tabular}{|c|c|c|}
\hline $\begin{array}{c}\text { Số lượng kháng sinh } \\
\text { trong một đơn }\end{array}$ & $\begin{array}{c}\text { Lượt } \\
\text { kề }\end{array}$ & $\begin{array}{c}\text { Tỷ lệ } \\
\mathbf{( \% )}\end{array}$ \\
\hline 1 kháng sinh & 125 & 91,91 \\
\hline 2 kháng sinh & 10 & 7,35 \\
\hline 3 kháng sinh & 1 & 0,74 \\
\hline Tống & $\mathbf{1 3 6}$ & $\mathbf{1 0 0}$ \\
\hline
\end{tabular}

Trong tống số 136 đơn thuốc có kháng sinh, số lượng đơn thuốc kê một kháng sinh duy nhất chiếm tỳ lệ cao nhất (hơn $91 \%$ ), các đơn thuốc có 2 hoặc 3 kháng sinh chỉ chiếm tỷ lệ nhỏ (lân lượt là $7,35 \%$ và $0,74 \%$ ). Chiếm phần lớn trong danh sách này chủ yếu là các kháng sinh nhóm Betalactam về mức độ phổ biến trong các đơn thuốc có kê kháng sinh. Trong đó, đứng đâu là là kháng sinh Midatan (Amoxicilin $500 \mathrm{mg}$ và Acid Clavulanic $125 \mathrm{mg}$ ) về số lần kê (20 lần kê tương đương 13,61\% tổng số đơn kháng sinh được kê).

3.3. Tỷ lệ đơn kê có thuốc tiêm. Việc kê thuốc tiêm vào đơn thuốc ở Trung tâm $Y$ tế huyện Phong Điền còn rất ít. Trong tổng số 385 đơn thuốc thì chỉ có 2 đơn thuốc có kê đơn thuốc tiêm chiếm tỷ lệ $2 \%$, còn số đơn không kê thuốc tiêm lên đến 383 đơn chiếm tỷ lệ $98 \%$. Có 2 loại thuốc tiêm sử dụng ngoại trú là thuốc tiêm dành cho người bị bệnh đái tháo đường để chống tăng đường huyết là Insulin aspart và Insulin glargine.

3.4. Tỷ lệ các đơon kê có vitamin. Số đơn thuốc không sử dụng vitamin chiếm tỷ lệ khá cao là $77,4 \%$ gấp gần 3,5 lần so đơn thuốc có sử dụng kháng sinh chỉ chiếm tỷ lệ là 22,6\%. vitamin là loại thuốc không có các mức tiêu chuẩn lý tưởng theo hướng dẫn của Tổ chức $Y$ tế Thế giới cũng như Bộ Y tế.

3.5. Tỷ lệ các đớn kê có corticoid. Với đơn không có thuốc chứa corticoid chiếm $73,8 \%$ cũng gấp xấp xỉ 3 lần đơn có thuốc chứa corticoid với tỷ lệ là $26,2 \%$.Theo khảo sát, Prednisolon $(71,17 \%)$ và Methyl prednisolon $(11,71 \%)$ là 2 loại corticoid phổ biến của thuốc corticoid, được các bác sĩ lựa chọn đầu tay trong điều trị tai các cơ sở y tế.

3.6. Tỷ lệ các thuốc được kê đơn có trong danh mục thuốc thiết yếu do Bộ $Y$ tế ban hành

Bảng 3.4. Tỷ lệ thuốc được kê nằm trong danh mục thuốc thiết yếu

\begin{tabular}{|c|c|c|}
\hline Cơ cấu thuốc & $\begin{array}{c}\text { Số } \\
\text { lượng }\end{array}$ & $\begin{array}{c}\text { Tỷ lệ } \\
(\mathbf{\%})\end{array}$ \\
\hline Trong danh mục thuốc thiết yếu & 910 & 45,64 \\
\hline Ngoài danh mục thuốc thiết yếu & 1084 & 54,36 \\
\hline Tống & $\mathbf{1 9 9 4}$ & $\mathbf{1 0 0}$ \\
\hline
\end{tabular}

Qua bảng 3.4, có thể thấy tỷ lệ thuốc được kê nằm trong danh mục thuốc thiết yếu tại Trung tâm Y tế huyện Phong Điền là 45,64\%.

3.7. Chi phí trung bình của đơn thuốc và tỷ lệ chi phí thuốc dành cho kháng sinh, thuốc tiêm, vitamin và corticoid

Bảng 3.5. Chi phí trung binh mỗi đơn thuốc Trung tâm $Y$ tế huyện Phong Điền

\begin{tabular}{c|c}
\hline \multicolumn{2}{c}{ Trung tâm Y tế huyện Phong Điên } \\
\hline Tống số đơn thuốc & 385 \\
\hline Tống chi phí đơn thuốc & 28.717 .209 \\
\hline Trung bình mõi đơn thuốc & $74.590,15$ \\
\hline
\end{tabular}

Chi phí trung bình mà bệnh nhân chi trả cho mỗi đơn thuốc tại Trung tâm $Y$ tế huyện Phong Điền là 74.590 đồng.

Bảng 3.6. Tý lệ chi phí trung binh cho đơn thuốc có kháng sinh, thuốc tiêm, vitamin và corticoid

\begin{tabular}{|c|c|c|}
\hline $\begin{array}{c}\text { Trung tâm Y tế huyện } \\
\text { Phong Điền }\end{array}$ & $\begin{array}{c}\text { Số } \\
\text { lượng }\end{array}$ & $\begin{array}{c}\text { Tỷ lệ chi } \\
\text { phí (\%) }\end{array}$ \\
\hline Đơn thuốc có kháng sinh & 136 & 38,28 \\
\hline Đơn thuốc có thuốc tiêm & 2 & 72,77 \\
\hline Đơn thuô̂́c có vitamin & 87 & 11,14 \\
\hline Đơn thuốc có corticoid & 101 & 7,98 \\
\hline
\end{tabular}

Với 136 đơn thuốc có chứa kháng sinh thì tỳ lệ chi phí trung bình mà bệnh nhân phải chi trả cho thuốc đơn đó là $38,28 \%$. Trong tổng số 2 đơn có chứa thuốc tiêm thì tỉ lệ chi phí trung bình chiếm khá cao trên $72 \%$, do các loại thuốc tiêm thường có giá thành khá đắt. Trong 87 đơn thuốc có vitamin thì tỉ lệ chi phí trung bình khá thấp, chỉ chiếm $11,14 \%$ trong mỗi đơn thuốc. Giống với đơn thuốc có vitamin, đơn thuốc có corticoid cũng chiếm tỉ lệ chi phí trung bình thấp, thấp nhất trong 4 loại thuốc, chỉ chiếm 7,98\%.

\section{BÀN LUÂ̂N}

4.1. Số thuốc kê trung bình trong một đơn. Số thuốc trung bình được kê đơn 5,18 ; kết quả nghiên cứu này cao hơn là 3,07 thuốc/đơn tại Iran. Nhóm nghiên cứu chỉ ra rằng tình trạng kê đơn có mối liên quan với giới tính, tuổi tác, tình trạng giáo dục, kinh nghiệm làm việc, tình hình kinh tế và chuyên môn của bác sĩ. Bên cạnh, mỗi khoa khác nhau nên sẽ có lượng thuốc kề ở mỗi đơn khác nhau. Kê nhiều thuốc trong đơn thường là khoa tim mạch do bệnh nhân mắc nhiều loại bệnh và kê ít thuốc nhất trong đơn là khoa mắt [1]. Theo một nghiên cứu của trường Đại học Groningen về các chỉ số sử dụng thuốc ở các quốc gia Đông Nam Á năm 2012 dao động từ 1,4-3,8, sự khác biệt này là do trình độ chuyên môn giữa các quốc gia hoặc do vị trí địa lý như thành thị và nông thôn[2].

Khi kê nhiêuu thuốc trong một đơn sẽ dẫn tới 
sự kém tuân thủ theo hướng dẫn điều tri của người bệnh, gia tăng chi phí, sử dụng thuốc không cần thiết và thậm chí còn có thể gây ra tương tác thuốc nguy hiểm cho người bệnh. Số lượng thuốc trong đơn tăng đồng nghĩa với tỷ lê xuất hiện phản ứng có hại và tương tác thuốc tăng: 16-20 thuốc trong một đơn thì tỷ lệ xuất hiện là $24,2 \%$ và trên 20 thuốc trong một đơn thì tỷ lê này lên đến $40 \%$. Bên cạnh đó, khi xét đến vấn đề kê đơn, cần đề cập đến khía cạnh yêu cầu từ người bệnh: mong muốn chữa nhiều bênh cùng một lúc hoắc do các phương tiện chẩn đoán bệnh không nhất quán để xác định nguyên nhân gây bệnh. Do đó, Hội đồng thuốc và điều trị bệnh viện cần tăng cường chỉ đạo và phối hợp giữa khoa Dược với các khoa lâm sàng, khoa khám ngoai trú, phòng cấp cứu,... nhằm cung cấp, cập nhật thông tin thuốc tới các bác sĩ thường xuyên nhằm giảm các tác dụng không mong muốn đối với các đơn có nhiều loai thuốc.

4.2. Tỷ lệ đơn kê có kháng sinh. Tỷ lệ đơn kê có kháng sinh trung bình là35,32\%. Một kết quả nghiên cứu tại Ấn Độ, tỷ lệ thu được khá cao $53,6 \%$, do bác sĩ có thể đánh giá quá cao mức độ nghiêm trọng của bệnh tật và biện minh cho việc kê đơn của nó. Bác sĩ cũng có thể bị căng thẳng do nhu cầu của bệnh nhân nhanh chóng giảm triệu chứng của các triệu chứng [3].

Khi đi sâu phân tích về các hình thức phối hợp kháng sinh trong đơn, kết quả cho thấy tỷ lệ kháng sinh đơn trị liệu cao (chiếm tỉ lệ 91,91\%). Sử dụng kháng sinh đơn trị liệu nhằm hạn chế nguy cơ đa kháng thuốc của vi khuẩn với nhiều loại kháng sinh khác nhau và hạn chế tác dụng phụ khi dùng nhiêu kháng sinh cùng lúc. Phối hợp kháng sinh trong điều trị cũng là một vấn đề luôn được quan tâm trong sử dụng kháng sinh hợp lý. Các trường hợp sử dụng 2 hoặc 3kháng sinh trong một đớn theo thống kê là do phối hợp 2 thuốc có đường dùng khác nhau, chủ yếu là đường uống và nhỏ mắt hoặc bôi ngoài da hoặc theo phác đồ điều trị viểm loét dạ dày do Helicobacter pylori. Kết quả cũng cho thấy, nhóm $\beta$ - lactam là nhóm thuốc được sử dụng nhiều nhất (tỉ lệ 69,93\%), kết quả này tương tự nghiên cứu tại Nigieria cho kết quả tương tự nhóm $\beta$ - lactam đạt tỷ lệ cao nhất: penicillin $(71,2 \%)$, cephalosporin $(15,8 \%)$ và nhóm macrolid với 8\% [4].

Hiện nay, vân đề kháng thuốc kháng sinh ở Việt Nam đáng báo động. Một trong các nguyên nhân dẫn đến kháng kháng sinh là do việc sử dung kháng sinh rộng rãi, quá liều hoăc kéo dài [5]. Sự lan tràn các chủng vi khuẩn kháng kháng sinh là vấn đề cấp bách nhất hiện nay. Sự xuất hiện các chủng vi khuẩn kháng kháng sinh ảnh hưởng đến hiệu quả điều trị và sức khỏe người bênh. Việc hạn chế sự phát sinh của vi khuẩn kháng kháng sinh là nhiệm vụ không chỉ của ngành y tế mà của cả cộng đồng nhằm bảo vệ nhóm thuốc này. Chỉ phối hợp kháng sinh nhằm mục đích tăng khả năng diệt khuẩn, giảm khả năng xuất hiện chủng đề kháng và điều trị nhiễm khuẩn do nhiều loại vi khuân gây ra [6].

4.3. Tỷ lệ đơn kê có thuốc tiêm. Chỉ có 0,52\% đơn thuốc có kê thuốc tiêm. Kết quả nghiên cứu này là phù hợp, cho thấycơ sở y tế không lạm dụng loại thuốc này và tỷ lệ này không vượt quá khuyến cáo của Tổ chức y tế thế giới. Tiến hành phân tích đơn thuốc, kêt quả có $100 \%$ là thuốc tiêm có chứa Insulin dùng cho người bệnh tiểu đường - đây cũng là loại thuốc tiêm BHYT cho phép sử dụng điều trị cho người bệnh ngoại trú.

Thuốc tiêm là loại thuốc khó dùng, đòi hỏi kỹ thuật cao. Bên cạnh đó, nguy cơ lây nhiễm virus HIV, virus viêm gan $B$ và $C$ hoặc các tai biến do sử dụng đường tiêm cũng được hạn chế đến mức tối thiểu. Vì vây khi quyết định lựa chon dạng thuốc cho người bệnh cần có sự cân nhắc kỹ càng và đủ điêu kiện theo dõi cẩn thận để đảm bảo an toàn tối đa cho người bệnh.

4.4. Tỷ lệ các đơn kê có vitamin. Tỷ lệ vitamin chiếm trung bình $22,6 \%$. Theo Tổ chức y tế thế giới, không có mức tiêu chuẩn lý tưởng cho tỷ lể đơn kê có vitamin. Bộ Y tế Việt Nam và môt số nước đưa chỉ số này vào nghiên cứu nhằm theo dõi tình hình sử dụng vitamin trong kê đơn, cũng như tránh tình trạng lạm dụng vitamin. Nghiên cứu của Goel R.K. cho tỉ lê cao hơn 30,22\%, nguyên nhân là do bác sĩ đánh giá cao mức độ nghiêm trọng bệnh tật của người bệnh để biển hộ cho việc kê đơn của họ. Bên cạnh ho cũng phải chiu áp lực từ bệnh nhân vì bệnh nhân muốn được kê thêm vitamin nếu không kê họ sẽ chán nản và thất vọng [7].

Vitamin $\mathrm{B} 6$ được sử dụng nhiều nhất với tỷ lệ $41,1 \%$. Trong mẫu nghiên cứu này, trên $80 \%$ là người bênh trên 40 tuổi, vitamin B6 cũng đóng một vai trò trong sự phát triển nhận thức, ngăn ngừa sa sút trí tuê và điếc thông qua quá trình sinh tổng hợp chất dẫn truyền thần kinh và duy trì mức homocysteine bình thường, một loại axit amin trong máu.

4.5. Tỷ lệ các đơn kê có corticoid. Tỷ lệ đơn kê có corticoid là $12,1 \%$. Tương tự vitamin, Tổ chức y tế thế giới và Bô $Y$ tế cũng không qui định mức giới hạn cho chỉ số này. Trong các 
corticoid được dùng prednisolon và methyl prednisolon được kê nhiều. Kết quả này khác với nghiên cứu tại Iran năm 2015 dexamethasone được kê toa nhiều nhất với tỉ lệ 15,27\%[1]. Các corticoid trong khảo sát chủ yếu dùng trong các điều trị viêm, hen suyễn hoặc bôi tại chỗ trong các chế phẩm dùng ngoài. Không có corticoid nào bị lạm dụng hoặc dùng sai so với các chẩn đoán.

Một số cán bộ y tế đều muốn người bệnh nhanh chóng khỏi bệnh nên thường chỉ định corticoid vì tính kháng viêm mạnh, giá thành thấp và luôn sẵn có tại cơ sở y tế. Do đó, cân hoàn thiện các cơ chế quản lý trong việc kiểm tra và giám sát công tác kê đơn của cán bộ y tế để hạn chế việc kê corticoid không cân thiết làm gia tăng chi phí cho người bệnh.

4.6. Tỷ lệ các thuốc được kê đơn có trong danh mục thuốc thiết yếu do Bộ Y tế ban hành. Tỷ lệ trung bình thuốc thiết yếu là $41,98 \%$. Kết quả thu được thấp hơn rất nhiều so với nghiên cứu tại Ethiopia 100\% (2014) [8]. Nghiên cứu tại Ethiopia cho thấy, nước này có chính sách thuốc thiết yếu và danh mụcthuốc thiết yếu quốc gia, các địa phương khác phải thực hiện theo qui định kê thuốc từ danh mụcthuốc thiết yếu này nên tỉ lệ này đạt tối đa.

Việc đảm bảo thuốc thiết yếu cho cộng đồng là một trong những vấn đề quan trọng nhất cho công tác chăm sóc và bảo vệ sức khỏe người dân, đặc biệt khi xét trên khía cạnh chi phí và hiệu quả. Để thực hiện được mục tiêu này, việc đảm bảo tiếp cận với các loại thuốc và quản lý chi phí thuốc ở mức phù hợp với khả năng chi trả của người dân đóng vai trò hết sức quan trọng.

4.7. Chi phí trung bình của mối đớn và tỷ lệ chi phí thuốc dành cho kháng sinh, thuốc tiêm, vitamin và corticoid. Chi phí tiên thuốc trung bìnhthu được là 74.590 đông. Với 136 đơn thuốc có chứa kháng sinh thì tỷ lệ chi phí trung bình mà bệnh nhân phải chi trà cho thuốc đơn đó là $38,28 \%$. Trong tổng số 2 đơn có chứa thuốc tiêm thì tỉ lệ chi phí trung bình chiếm khá cao trên $72 \%$, do các loại thuốc tiêm thường có giá thành khá đắt. Trong 87 đơn thuốc có vitamin thì tỉ lệ chi phí trung bình khá thấp, chỉ chiếm $11,14 \%$ trong mỗi đơn thuốc. Giống với đơn thuốc có vitamin, đơn thuốc có corticoid cũng chiếm tỉ lệ chi phí trung bình thấp, thấp nhất trong 4 loại thuốc, chỉ chiếm 7,98\%.

Vấn đề về chi phí thuốc là mối quan tâm thường xuyên của xã hội. Giá thuốc ảnh hưởng có ý nghĩa đến việc lựa chọn thuốc để kê đơn. Tất cả các quốc gia nên xác định giá của các thuốc thiết yếu, các chính sách thích hợp cũng như quản lý các thông tin về giá cạnh tranh.

Tại Việt Nam, bắt đầu từ năm 1993, công tác quản lý thuốc dân dân được củng cố, việc đăng ký thuốc, công ty nước ngoài đăng ký kinh doanh thuốc tại Việt Nam, việc phát triển sản xuất thuốc nội địa đã góp phân làm ổn định trât tự thị trường thuốc, giá thuốc từ đó cũng ổn định hơn. Thông tư Liên tịch 01/2012/TTLT-BYTBTC về việc hướng dẫn đấu thâuu mua thuốc trong các cơ sở y tế có hiệu lực từ 06/2012. Thông tư có mục đích giảm ngân sách bảo hiểm y tế và giảm tiên thuốc cho người bệnh bằng cách đấu thâu mua loại thuốc rẻ cho các bệnh viện. Theo báo cáo 2014 của Bộ Y tế về việc đấu thầu, mua thuốc tại các cơ sở y tế có hiệu lực từ tháng 06/2012 với mục đích giảm ngân sách bảo hiểm y tế và giảm tiền thuốc cho người bệnh bằng cách đấu thâu mua loại thuốc rẻ cho các bệnh viện. Các quy định mới về đấu thâu thuốc đã் đảm bảo cả hai yếu tố chất lượng và giá thuốc, giá thuốc trúng thâu theo quy định mới về đấu thâu đã giảm và giúp tiết kiệm $35 \%$ chi phí mua thuốc tại các cơ sở y tế trển cả nước, góp phân làm bình ổn thị trường dược phẩm.

\section{KẾT LUẬN}

Qua phẩn tích các đơn thuốc tại Trung tâm Y tế huyện Phong Điền:

Số thuốc trung bình trong một đơn là 5,18.

Tỷ lệ đơn thuốc có kháng sinh chiếm 35,32\%, đơn thuốc có thuốc tiêm chiếm tỷ lệ rất thấp chỉ $0,52 \%$, đơn thuốc có vitamin và corticoid chiếm tỷ lệ lấn lượt là 22,60\%,26,20\% trong tổng sô 385 đơn thuốc tại Trung tâm $Y$ tế huyện Phong Điên.

Trong các đởn thuốc có kháng sinh, tỷ lệ đơn có 1 kháng sinh chiếm 91,91\%, cao hơn hẳn đơn thuốc có phối hợp 2 hoặc 3 kháng sinh.

Đối với tỷ lệ thuốc được kê nằm trong danh mục thuốc thiết yếu, số lượng thuốc kê nằm trong danh mục là 910 chiếm tỷ lệ 45,64\%.

Chi phí trung bình cho mỗi đơn thuốc tại Trung tâm $Y$ tế huyện Phong Điền là hơn 74.590 VNĐ. Tỷ lệ chi phí cho kháng sinh chiếm $38,28 \%$, thuốc tiêm chiếm $72,77 \%$; vitamin là $11,14 \%$; corticoid chiếm 7,98\%.

\section{TÀI LIÊU THAM KHẢO}

1. Karimi A., Haerizadeh M., Soleymani F., et al. (2014). Evaluation of medicine prescription pattern using World Health Organization prescribinq indicators in Iran: A cross-sectional study. Journal of research in pharmacy practice, 3(2):39-45.

2. Nguyen H.T., Wirtz V.J., Haaijer F.M., et al. (2012). Indicators of quality use of medicines in South-East Asian countries: a systematic review. Tropical Medicine and International Health, 
17(12):1552-1566.

3. Shelat P.R., Kumbar S.K. (2015). Analysis of out door patients' prescriptions according to World Health Organization (WHO) prescribing indicators among private hospitals in Western India. Journal of Clinical and Diagnostic Research, 9(3):1-4.

4. Fadare J., Oladele 0. , Oludare 0. et al. (2015). Drug prescribing pattern for under-fives in a paediatric clinic in South-Western Nigeria. Ethiopian Journal of Health Sciences, 25(1):73-78.

5. Bô̂ Y tế (2017). Quyết định số 4041/QĐ-BYTngày 07 tháng 9 năm 2017 về việc ban hành Đề án tăng cường kiểm soát kê đơn thuốc và bán thuốc kê đơn giai đoan 2017-2020, Hà Nội.

6. Bô Y Tế (2016). Quyết đinh số 772/QĐ-BYT về việc ban hanh tài liệu "Hướng dẫn thực hiện quản lý sử dụng kháng sinh trong bệnh viện", Hà Nội.

7. Goel R.K., Bhati Y., Dutt H.K., et al. (2013). Prescribing pattern of drugs in the outpatient department of a tertiary care teaching hospital in Ghaziabad, Uttar Pradesh. Journal of Applied Pharmaceutical Science, 3(4):48-51.

8. Bantie L. (2014). Assessment of prescribing practice pattern in governmental health centers of Bahir Dar Town, Ethiopia. World Journal of Pharmaceutical Sciences, 2(10):1184-1190.

\section{TUÂN THỦ ĐIỀU TRI TIÊTT TRỪ' HELICOBACTER PYLORI VÀ CÁC YẾU TỐ LIÊN QUAN Ở BÊ̂NH NHÂN ĐIỀU TRI NGOẠI TRÚ TẠI BỆNH VIỆN QUẬN 2, TP. HCM}

\section{TÓM TẮT}

Đặt vấn đê: H.pylori có liên quan đến loét tá tràng và da dày, có thể dẩn đến xuất huyết tiêu hóa, thủng da dày và ung thư da dày. Tại Việt Nam, tỷ lệ nhiếm H.pylori trên bệnh nhẩn loét dạ dày tá tràng tự 60 đến $80 \%$ tuy nhiên hiệu quả điều trị H.pylori giảm dần từ $90 \%$ trong thập kỷ 90 xuống còn $60-70 \%$ sau năm 2010. Tỷ lê này liên quan đến tình trang kháng thuốc kháng sinh do người bệnh không tuân thủ điều trị. Đối tượng và phương pháp: Thiết kế cắt dọc trên 249 bênh nhân điều trị tiệt trừ H.pylori lần đâu, trên 18 tuổi. Bểnh nhân có kết quả cân lâm sàng $(+)$ sẽ được mời vào nghiên cứu và thu thập các thông tin dân số - xã hôi và lâm sàng. Sau khi uống thuốc 2 tuần sẽ tái khám và được đánh giá tuân thủ điêu trị. Đánh giá tuân thủ điều tri bao gồm 2 khía canh: tuân thủ thuốc và tuân thủ khônng dùng rượu bia, thuốc lá. Kết quả: Tỷ lệ tuân thủ thuốc, tuân thủ không uống bia rượu - thuốc lá, tuân thủ chung lần lượt là $84,74 \%, 95,58 \%$ và $83,13 \%$. Có mối liên quan có ý nghĩa thống kê giữa tuân thủ điều tri và: giới tính nữ $(R R=1,16 ; p=0,011)$, đi khám với mục đích tầm soát $(R R=1,17 ; p=0,033)$, có các bênh kèm theo $(R R=1,17$ lần; $p=0,012)$, đước tư vấn ( $(R R=1,16$ lần; $p=0,016)$, không có tiên sứ hút thuốc lá $(R R=1,87 ; p<0,001)$ và uống rượu bia $(R R=2,27 ; p<$ 0,019). Kết luận: Tî lệ tuân thủ thấp cho thây cần cải thiên khâu tư vấn và giáo duc sức khỏe.

Tư khóa: Tuân thủ điểu trị, H.pylori, điều trị tiệt trừ, tư vấn

\section{SUMMARY \\ COMPLIANCE WITH HELICOBACTER PYLORI}

*Bệnh viện Quận 2, TP Hồ Chí Minh

**Trướng $Đ H$ Y khoa Pham Ngoc Thach

Chịu trách nhiệm chính: Trân Đức Sĩ

Email: sitd@pnt.edu.vn

Ngày nhận bài: 2/1/2021

Ngày phản biên khoa hoc: 1/2/2021

Ngày duyệt bài: $1 / 3 / 2021$

\section{Hoàng Hải*, Trần Đức Sĩ *}

\section{TREATMENT AND RELATED FACTORS IN OUT PATIENTS AT DISTRICT 2 HOSPITAL, HCMC}

Introduction: $H$. pylori has been proved to be related to duodenal and gastric ulcers, which can lead to gastrointestinal bleeding, perforation and gastric cancer. In Vietnam, the prevalence of $\mathrm{H}$. pylori infection in patients with peptic ulcer is from 60 to $80 \%$. However, the effect of $\mathrm{H}$. pylori treatment gradually decreased from $90 \%$ in the 1990 s to 60 $70 \%$ after 2010 . This rate is related to antibiotic resistance due to the non-compliance of patients. Subjects and method: We recruitedin our prospective, cross-sectional study 249 adults with $\mathrm{H}$. pyloriwho were undergoing an eradication treatment for the first-time. Patients with $\mathrm{HP}(+)$ will be invited in study and asked for socio-demographic and clinical information. After 2 weeks of medication, a follow-up visit has been made and the compliance would be assessed. Compliance assessment according to the WHO definition includes 2 criteria: drug compliance and non-alcohol and tobacco compliance. Results: Therates of drugs compliance, nonalcohol-tobacco compliance, and general compliance were respectively $84.74 \%$, $95.58 \%$ and $83.13 \%$. There was a statistically significant association between adherence to treatment and: female sex $(R R=1.16 ; p=0.011)$, detected bygeneral check ( $R R=1.17 ; p=0.033)$, having comorbidities ( $R R=1.17 ; p=0.012)$, be counseled ( $R R=1.16 ; p=0.016)$, no history of smoking $(R R=1.87 ; p<0.001)$ and no history of drinking $(R R=2.27 ; p<0.019)$. Conclusion: Low compliance indicates a need for improvement in health education and counseling.

Keywords: Treatment compliance, H.pylori, eradication treatment, counseling

\section{I. ĐĂTT VẤN ĐỀ}

Helicobacter pylori (H.pylori) là một loại xoắn khuẩn gram âm vi hiếu khí chủ yếu lây nhiễm vào niêm mạc dạ dày. Nguy cơ mắc viêm loét dạ 